\title{
Obesity Treatment Strategies
}

\author{
lanosi Edith Simona*, Comes Alexandra, Jimborean Gabriela
}

University of Medicine and Pharmacy of Tirgu Mures

Obesity is a disease with severe health consequences and increased risk of mortality. The most commonly used criteria to assess the presence and the severity of obesity are body mass index, waist circumference, waist-to-height ratio and the presence of the health conditions caused or worsened by obesity. Worldwide obesity has more than doubled in the last 4 decades. Obesity is the second of the leading preventable causes of death worldwide (after smoking). Obesity has a plurifactorial pathogenesis. The central perturbation consists in the imbalance between calories intake and calories consumption (by inappropriate diet and sedentary lifestyle). Identification of all the ethiological factors is important for treatment and prophylaxis. Weight loss benefits are multiple and important: improvement in glicemic control and in plasma lipid levels, blood presure control, obstructiv sleep apneea reduction, improvement in management of daily activities and profesional performances, increase quality of life, reduction in mortality. Overweight or obese patient will complete a diagnostic and a treatment program. Treatment of obesity claims a targeted multidimensional therapy: weight and lifestyle management, diet, sustained physical activity in daily life, exercise, decrease life stressors, smoking cessation, drug therapy, bariatric surgery psichological, familial and social suport. Weight loss program must be carefully planned, adapted to the patient's abilities and comorbidities and supervised by a nutritionist and a physiotherapist.

Keywords: Obesity, comorbidities, diet, exercise, bariatric surgery, social support

Received: 24 June 2015 / Accepted: 31 July 2015

\section{Background}

Nowadays obesity is considered a chronic disease being also a severe individual health condition and an important public health problem. Obesity is due to an excess of body fat accumulation which leads to severe health consequences and a significant percentage of mortality [1]. Most often obesity is defined by "Body Mass Index" (BMI). BMI is a measuring tool for assessing obesity based on individual's weight and height. BMI does not actually measure the percentage of body fat but is still used as a standard measure of obesity and a simple criteria to indicate the need of lifestyle changes, medical or surgical interventions against obesity. The World Health Organization (WHO) established the values for obesity definition based on BMI [1]:

- Underweight (BMI $\leq 18.5)$

- Normal weight (BMI 18.5 - 24.9)

- Overweight (BMI 25.0 - 29.9)

- Obesity (BMI 30.0 - 34.9) or Class I obesity

- Severe obesity (BMI 35.0 - 39.9) or Class II obesity

- Morbid obesity (BMI $\geq 40.0$ ) or Class III obesity

BMI is not always an accurate predictor of body fat or fat distribution, particularly in muscular individuals because of the existent differences of fat and muscle proportion and distribution. Other instruments to describe obesity, fat distribution, cardiovascular risk and mortality are: waist circumference (WC), waist-to-height ratio (WHtR) and waist-to-hip ratio (WHR) [1,2]. WHtR is considered the best prospective indicator of cardiovascular risk as demonstrated several cross-sectional studies $[3,4,5]$. The American Heart Association recommended $102 \mathrm{~cm}$ for men and $88 \mathrm{~cm}$ for women as cutoff levels for WC,

* Correspondence to: Edith Simona lanosi

E-mail: ianosi_edith70@yahoo.com and 0.95 for men and 0.88 for women as cutoff levels for WHR $[6,7]$.

\section{Epidemiology of obesity Morbidity:}

- Worldwide obesity has more than doubled in the last 4 decades [8];

- In 2008, 1.5 billion adults (older than 20) qualified as overweight. Of these, over a third were obese [1,9];

- Over two-third of adults in the United States are overweight or obese, and over one-third are obese, according to data from the National Health and $\mathrm{Nu}-$ trition Examination Survey (NHANES) 2007-2008. WHO predicts that by 2015 approximately 2.3 billion adults will be overweight and more than 700 million will be obese $[1,10,11]$;

- In 2005, at least 20 million children under the age of 5 were overweight. In 2010 nearly 43 million children under the age of 5 were overweight $[12,13]$;

- In 2010 in US 15\% of adolescents and children were obese (1 in 6) [1,13];

Mortality attributable to obesity:

- Obesity is associated with increased risk of illness, disability, death and financial costs;

- Approximately 300,000 deaths per year may be attributable to obesity [14];

- Obesity is the second preventable cause of death worldwide, immediately after smoking [15];

- The mortality risk is lower at a BMI of $20-25 \mathrm{~kg} / \mathrm{m}^{2}$ in non-smokers [16];

- A BMI above 32 has been associated with a significantly higher mortality rate in women at a 16 years follow-up and in Europe, $7.7 \%$ of deaths are related to excess weight $[11,17]$; 
- On average, obesity reduces life expectancy by six to seven years [18];

- Severe obesity $(\mathrm{BMI}>40)$ reduces life expectancy by 10 years [19];

- In 2008, obesity-related medical care costs were over $\$ 147$ billion [20];

- In two time periods of two years each taken as reference, annual hospital costs related to obesity among children and adolescents increased 4 times [21].

\section{The health consequences of obesity}

The health consequences of obesity are: physical, psychological and social. The multiple medical complications of obesity are notified in table I [1,5,6,22,23,24]:

Table I. Health consequences of obesity

\begin{tabular}{|c|c|}
\hline $\begin{array}{l}\text { Cardiovascular } \\
\text { diseases }\end{array}$ & $\begin{array}{l}\text { Ischemic heart disease and stroke [24] } \\
\text { High blood pressure } \\
\text { Venous stasis, phlebitis } \\
\text { Deep vein thrombosis, pulmonary embolism [25] }\end{array}$ \\
\hline \multicolumn{2}{|c|}{ Metabolic diseases: diabetes mellitus, dyslipidemia, gout [5] } \\
\hline $\begin{array}{l}\text { Osteo-arthro- } \\
\text { muscular } \\
\text { disorders }\end{array}$ & $\begin{array}{l}\text { Osteoarthritis } \\
\text { Lower back pain, poor mobility }\end{array}$ \\
\hline \multicolumn{2}{|c|}{$\begin{array}{l}\text { Increase risk for cancer - endometrial, breast, cervix, colon, prostate, kidney } \\
\text { [16] }\end{array}$} \\
\hline $\begin{array}{l}\text { Respiratory } \\
\text { disorders [24] }\end{array}$ & $\begin{array}{l}\text { Adult-onset asthma } \\
\text { Sleep apneea and sleeping disorders [26] } \\
\text { Hypoventilation - obesity syndrome }\end{array}$ \\
\hline $\begin{array}{l}\text { Digestive dis- } \\
\text { orders }\end{array}$ & $\begin{array}{l}\text { Hernia } \\
\text { Gallstone, hepatic steatosis, severe pancreatitis }\end{array}$ \\
\hline $\begin{array}{l}\text { Genital abnor- } \\
\text { malities [24] }\end{array}$ & $\begin{array}{l}\text { Menstrual irregularities or cessation of menstruation } \\
\text { (amenorrhea) } \\
\text { Decreased fertility and pregnancy complications } \\
\text { Polycystic ovarian syndrome, hypogonadism } \\
\text { Erectile dysfunction }\end{array}$ \\
\hline Skin disorders & $\begin{array}{l}\text { Skin lesions arising from the bacterial breakdown of sweat } \\
\text { Intertrigo, cellulites, lymphedema, hirsutism }\end{array}$ \\
\hline \multicolumn{2}{|l|}{ Catharacta } \\
\hline Emotional a & al problems (stigmatization) [24] \\
\hline
\end{tabular}

\section{Causes of obesity}

Obesity has a plurifactorial pathogenesis. A complex combination of factors (internal and external environmental factors) contributes to the weight excess. The central perturbation consists of the imbalance between calories intake and consumption (inappropriate diet and sedentary lifestyle). Identification of all the ethiologic and risk factors is important for treatment and prophylaxis. There are several conditions which explain most obesity [22,27].

\section{Genetic factors in obesity}

- Genetic predisposition to weight gain varies between $6-85 \%$ (25\% average) upon populations. The heritability of weight, regulation of weight, metabolic rate, thermic responses to food, body composition and spontaneous physical activity have complex polygenic determinacy $[5,31]$

- Some genes disorders were already identified:

- Increased "agouti-related protein" was found in higher concentration in obese people, in hypothalamus (food intake modulating site) $[28,29]$;
- Melanocortin-4 (MCR-4) receptor gene defects;

- Leptin gene and leptin receptor gene defects (leptin is produce in fat cells, gut and placenta and inhibits food intake inhibiting neuropeptide $\mathrm{Y}$ in arcuate nucleus). Leptin deficiency or resistance to leptin stimulates food intake [30];

- Genetic predisposition to type 2 diabetes promotes weight gain $[14,32]$.

- Family history reflects genetic susceptibility and environmental exposures shared by close relatives. Physicians have to ask about family health history to identify people at high risk of obesity and of obesity-related disorders. Weight loss or prevention of excessive weight gain is especially important in this high-risk group [8];

\section{Age and gender}

- Age and gender differences in food intake and weight gain have been identified with an increase in adolescence, peaking in the second decade after which it declines [33];

- The decline in sex steroid levels occurring in the perimenopause results in an increase in visceral fat and an increased risk of the metabolic syndrome development. Women are at higher risk for more severe obesity at menopause [14,32];

- Most excess weight before puberty is gained before 5 years of age. Weight at 5 years of age bears little relation to birth weight but closely predicts weight at 9 years of age and future metabolic risk [33]. Most likely an obese child will become an obese adult [13].

\section{Environmental factors}

Environmental factors are the prime causes of modern obesity. The fact that obesity has increased dramatically in the last decades appears to disconsider genetics as a major main cause.

- Nutrient imbalance (beetween intake and energy consumtion) is playing the key role $[1,6,8,10]$ :

- The high food intake, especially the amount of fat

- Low energy expenditure, sedentary lifestyle, low physical activity

- Family influence in lifestyle (especially for obese children)

- The type of eaten food -"Obesogenic environment". The high-fat/high-sugar food produces addiction to food similar to drug abuse by dopamine deficiency. Studies with positron emission tomography (PET) have shown that exposure to high-fat diet over a number of weeks caused a reduction in Dopamin2Receptors and a dysfunction in the reward capacity. The result is over-eating to compensate the dopamine deficiency [34];

\section{Disregulation in Central Nervous System}

Disregulation in Central Nervous System (hypothalamus + limbic system) in processing the peripheral and central signals concerning appetite, satiety. 
- Disregulation occurs in the homeostatic control of eating (hypothalamic level) and in the hedonic system (pleasure of eating) located in the limbic system leading to overeating and obesity [35].

- Stress, depression, low self-esteem, insufficient sleep, mental illness [10];

\section{Endocrinologic disorders}

Endocrinologic disorders (hypothyroidism, Cushing's syndrome, testosterone deficiency, polycystic ovarian syndrome, insulinoma, hypothalamic lesions and genetic syndromes) often present with obesity. The fat cell is considered an endocrine organ that produces several peptides that participate in the regulation of adipocyte function [36];

\section{Other conditions:}

- Smoking cessation;

- Pregnancy at an advanced maternal age, which may cause susceptibility to obesity in children [27];

- Retirement conditions [10].

\section{Obesity management strategies}

The increasing number of individuals with obesity and the multiple negative consequences of obesity have increased the medical attention for prophylaxis and development of safe and efficacious treatment strategies. Multidimensional pathogenesis of obesity claims a careful and targeted multidimensional therapy. Obesity and its related comorbidities are largely preventable. Weight loss (WL) benefits are multiple and important $[6,7,8,10,37,38,39]$ :

- Improvement in glicemic control,

- Reduction in LDL cholesterol, TG, CRP,

- Blood pressure control,

- Increase in HDL cholesterol,

- Improvement in comorbidities (diabetes control, obstructiv sleep apneea reduction) [40],

- Improvement in management of daily activities and professional performances,

- Increased life quality,

- Reduction of mortality,

- For $10 \%$ WL there is about $30 \%$ loss of visceral adipose depots.

The current therapeutic approaches for obesity treatment include [1]:

- Weight and lifestyle management

- Diet

- Exercise

- Drug therapy

- Bariatric surgery

- Psychological, familial and social support

\section{Weight and lifestyle management}

Overweight or obese patients will be included in a complete diagnostic and treatment program which will contain:
- Assessment of BMI (weight and high), WC, sex, age, medical history, occupation, smoking, alcohol use;

- Questionnaire about physical activity, nutrition, lifestyle, psychological condition, sleep, quality of life perception ;

- Assessment of the related conditions and obesity complications: diabetes mellitus, obstructive sleep apneea (OSA), hypertension, cardiovascular function (clinical exam, EKG, heart ultrasound), dislypidemia, gout, osteoarthritis, hypothyroidism, cancer;

- Therapeutic plan setting (self-monitoring under supervision from an exercise physiologist and a nutritionist) $[7,9,39,41]$ :

- Figuring the ideal BMI but establishing realistic goals

- Sustained physical activity in daily life

- Exercise plan

- Diet plan

- Psychological, familial and social support

- Decrease life stressors

- Smoking cessation

- Avoidance of sedative and alcohol use

- „Stress management” education

Treatment of comorbid conditions

The weight control program must be individually customized to the patient in order to achieve a desirable outcome.

\section{Dietary changes for weight loss}

Diet programs in obesity treatment include slow weight loss (WL) and than maintaining the WL like a permanent preoccupation and part of a person's lifestyle. Success rates of long-term WL maintenance are low, ranging from 2-20\% [39]. Diet program characteristics [10]:

- Diet has to establish individual realistic goals $(5-10 \%$ WL)

- Diet must be individualized to the patient for long term weight control [24]

- Diet should fit the needs of the patient

- A diet should be natural and easy to follow: three main meals daily, plus one or two snacks

- Important diet details:

- limit energy intake from total fats;

- increase consumption of fruit and vegetables, as well as legumes, whole grains and nuts;

- limit the intake of sugar and avoid alcohol use.

- Self-monitoring diet under supervision of a nutritionist (follow up) [24]:

- Monitoring the WL minimum 3 months

- if unsuccesfull WL at 3 months $(<5 \%) \rightarrow$ repeat firstline advice $\rightarrow$ control at 6 months

- if unsuccessfull WL at 6 months $\rightarrow$ dietetitian reassesment and consider pharmacotherapy

- successfull WL (> 5\% at 3 months and $>10 \%$ at 6 months) $\rightarrow$ maintenance phase with control (monthly reassessments)

The basic principle which must take into account in any diet is that WL depends on caloric deficit and caloric 
deficit depends on total calories, not on the type of calories consumed compared to calories. The diet must have a conventional distribution: carbohydrates $55 \%$ of total calories, fat $30 \%$ and protein $15-20 \%$ of total calories [37].

Traditional methods: low-calories diets" 800-1,500 cal. a day

- Low fat (the total daily fat limit should be 40 grams; the total daily saturated fat limit would be 13 gramms $-10 \%$ calories from fat)

- High fiber diet 20 to $30 \mathrm{~g} /$ day

- Under $6 \mathrm{~g}$ of sodium chloride/day

- Provide 0,25 - $0.75 \mathrm{~kg}$ of fat loss/week

- Long-term healthy diet $\rightarrow$ low fat, high complex carbohydrate, rich in vegetable fibers

New methods: „Very Low-calories diets” [41]

- For short-term WL (BMI > 30)

- Prepared formulas of $800 \mathrm{cal}$ or less which replace all usual food intake

- Provide 1.5 to $2.5 \mathrm{~kg}$ of fat loss/week, for a total WL of $22 \mathrm{~kg}$ over 12 weeks

- Not appropriate for children or adolescents

\section{Increased activity and exercise}

Increased physical activity and regular exercise are considered a desirable complement to dieting and they have the added benefit of improving other parameters, such as followed [11]:

- Increase energetic expenditure

- Fat loss (especially visceral fat)

- Attenuation of muscle mass loss, developing muscle mass and increasing muscle tone

- Increase thermogenetic response and the basal metabolism (BM)

- Increase insulin sensibility, improve lipids profile

- Decrease hypertention

- Psychological benefit

Exercise program must be carefully planned, adapted to the patient's abilities and physical condition and at least the initial few weeks supervised by a physiotherapist. In 2008, in US were launched the "Physical activity guidelines for adults" which stipulate the effective program of organized exercise as adjunct in combating obesity [7]. The main recommendations are:

- Avoid inactivity, increase daily activities

- Regular exercise:

- At least 150-300 min (2,5 h-5h) a week of moderate-intensity or $75-150 \min (1,15 \mathrm{~h}-2,3 \mathrm{~h})$ a week of vigorous-intensity aerobic physical activity;

- Muscle-strengthening activities which involve all major muscle groups;

- Continuation of physical activity for at least two years from the start of the WL intervention will enhance the maintenance of the WL.

\section{Drug therapy for weight loss}

The inadequate efficacy of exercise and diet especially in severe obese individuals coupled with their poor long-term success has focused research efforts on other strategies, including pharmacotherapy and bariatric surgery [23]. Despite of intensive researches there are few drugs approved for treating obesity. The main drugs used are described in table II [22,23,38].

Pharmacological targets for obesity treatment consist of multiple targets and include:

- Inhibition of appetite (sibutramine)

- Inhibition of fat absorption (orlistat)

- Weight-regulatory brain circuits (cannabinoid receptor-1 (CB1) antagonists)

- Metabolism stimulation (CB1 antagonists; drugs that stimulate uncoupling proteins).

Choosing the correct WL therapy depends on many factors: long-term safety experience, WL capability, drugs side-effects, patient comorbidities. Drug combination association of 2 or more WL medication - improves outcomes and total WL.

Drug therapy for WL is limited by contraindications, adverse effects and high costs (Sibutramine was retired in 2010 because of cardiovascular risk). Recommandation of the „Expert Panel on the Identification, Evaluation and Treatment of Overweight and Obesity" is very specific „Drugs that induce weight loss approved by FDA may be used only as part of a weight loss program including diet and physical activity for patients with BMI> 30 without concomitant diseases or risk factors due to obesity and for patients with BMI $=27$ to the disease or risk factors due to obesity. Drugs will never be used without concomitant lifestyle modification. It is necessary to continue evaluating the efficacy and safety in drug therapy management. If drugs are useful in achieving or maintaining weigh loss and its adverse effects are minor they can be used, if not drugs will be discontinued" [23].

\section{Bariatric Surgery}

Bariatric surgery (BS) is now considered the most efficacious treatment for reducing excess body weight. The gastrointestinal tract is transformed by surgery until decreases intraluminal capacity for food. This can be achieved using the gastric banding technique (using an implanted medical device), the sleeve gastrectomy or biliopancreatic diversion with duodenal switch (including removal of a portion of the stomach) or using gastric bypass surgery, by resecting and re-routing the small intestine to a small stomach puch $[17,42,43]$.

The predominantly restrictive procedures (vertical banded gastroplasty, sleeve gastrectomy, gastric banding) reduce the stomach size in order to limit the gstric volume, promote early satiety and thus reduce the oral intake. These techniques leave the alimentary canal in continuity and do not lead to food malabsorption [12]. 
Table II. Drug therapy for weight loss

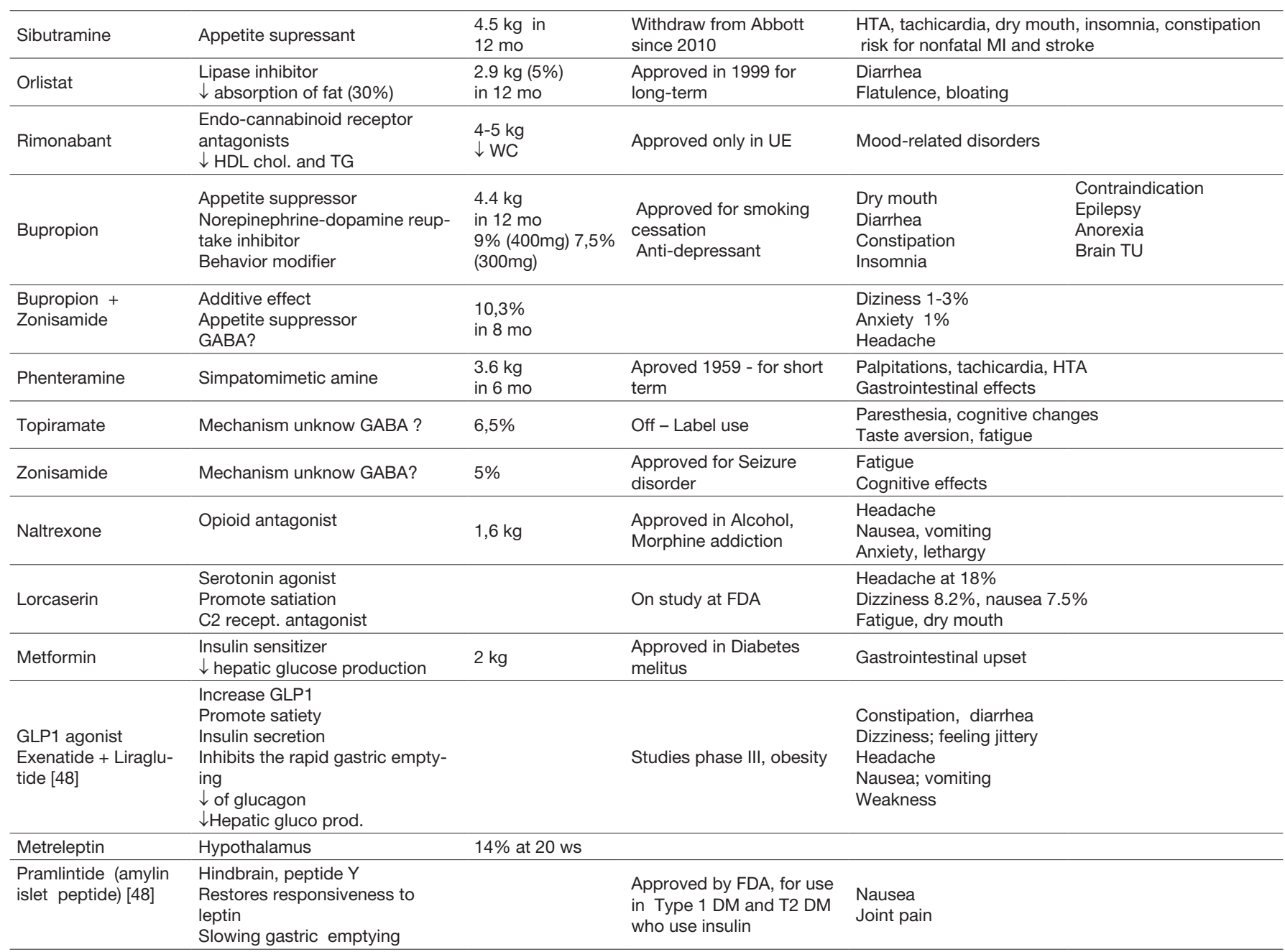

The predominantly malabsorptive procedures (biliopancreatic diversion, endo-luminal sleeve) and the mixed procedures (gastric bypass surgery, sleeve gastrectomy with duodenal switch) by re-routing of food away from much of the small intestine to partially prevent absorption of food $[12,43,44]$.

The degree of WL achieved by BS is significantly higher than other treatment measures and the $\mathrm{WL}$ is long-lasting in the majority of the subjects [45].

Overall, patients undergoing BS showed many benefits:

- Reduction of appetite and significant WL

- Reduction in the severity of symptoms of diabetes $[46,47]$

- Improvement in cardiovascular risk factors, control of hypertension

- Improvement in mobility

- Return of fertility

- Significant improvement in OSA (any decrease with $15 \mathrm{~kg} / \mathrm{m}^{2}$ in BMI associates a decrease with 36 OSA events/h in the apneea/hypopneea index)

- Significant improvement in quality of life

- Decrease in mortality [45]

The responsible mechanisms for the decreased appetite and remission of diabetes are unknown, but probably in- clude some combination of enhanced nutrient stimulation of the distal intestine and consequent enhanced release of incretin hormones (GLP-1), reduced stimulation of the proximal intestine [47]. Bariatric Surgery should be considered as a treatment option for patients with:

- BMI of $40 \mathrm{~kg} / \mathrm{m}^{2}$ or greater

- Weight $>45 \mathrm{~kg}$ over the ideal

- Previous failure of an adequate exercise and diet program

- Comorbid conditions (OSA, type II diabetes, hypertension, gastroesophageal reflux, urinary incontinence, infertility, osteoarthritis, etc.) without contraindications for major surgery

- 18-50 years old

- Appropriate motivation and psychological stability to understand risks/benefits

- Committed to lifelong post-operatory lifestyle changes (healthy nutrition + regular physical activity)

Young obese patients, with a $\mathrm{BMI}<50 \mathrm{~kg} / \mathrm{m} 2$, who underwent surgery, can have a mortality of $1 \%$ even in the absence of any comorbidity. At the same time, massively obese patients with a BMI $>60 \mathrm{~kg} / \mathrm{m}^{2}$ who are also diabetic, hypertensive or with cardiopulmonary failure may have mortality rates ranging between $2-4 \%[12,45]$. 


\section{References}

1. WHO - Obesity and overweight. Fact sheet Nr. 311, Updated March 2011.

2. Feller $\mathrm{S}$, Boeing $\mathrm{H}$, Tobias Pischon $\mathrm{T}$. Body Mass Index, Waist Circumference, and the Risk of Type 2 Diabetes Mellitus. Dtsch Arztebl Int. 2010. 107(26):470-476.

3. vanDis I, Kromhout D, Geleijnse JM, Boer JM, Verschuren WM - BMI and WC predict both 10-year nonfatal and fatal cardiovascular disease risk: study conducted in 20,000 Dutch men and women aged 20-65 years. Eur J Cardiovasc Prev Rehabil, 2009, 16(6):729-734.

4. Pischon T, Boeing H, Hoffmann K, et al. General and abdominal adiposity and risk of death in Europe. N Engl J Med, 2008, 359:2105-2120.

5. Zhang C, Rexrode KM, van Dam RM, Li TY, Hu FB. Abdominal obesity and the risk of all-cause, cardiovascular, and cancer mortality: sixteen years of follow-up in US women. Circulation. 2008;117:1658-1666.

6. American Heart Association febr. 2011 - Heart and stroke facts. Dallas; 2011.

7. U.S. Depart of Health and Human Services NIH 2009. Weight-control Information Network. Physical Activity Guidelines for Americans. Oct. 2008. Available at http://www.health.gov/paguidelines.

8. Centers for Disease Control and Prevention. Youth Risk Behavior Surveillance United States, Morbidity \& Mortality Weekly Report, 2008;57:SS-4

9. Ryan Donna, David M Kendall, John Blundell, Ken Fujioka. Strategies to Combat Obesity: The Role of Appetite. Regulation and Impulse Control Authors and Disclosures. 2011 January 28.

10. Bogle Vanessa. Haringey Obesity Strategy. 2007-2010.

11. Tsigosa C, H Vojtech, Basdevant A, Finer N, Fried M, Mathus-Vliegen Elisabeth et al. Management of Obesity in Adults: European Clinical Practice Guidelines. The European Journal of Obesity. 2008;1(2):106116.

12. Abell TL, Minocha A. Gastrointestinal complications of bariatric surgery: diagnosis and therapy. Am J Med Sci. 2006;331(4):214-218.

13. Han JC, Lawlor DA, Kimm SY. Childhood obesity. Lancet. 2010;375:1737-1748.

14. Allison DB, Fontaine KR, Manson JE, Stevens J, Vanltallie TB. Annual deaths attributable to obesity in the United States. JAMA. 1999;282(16):1530-1538.

15. Barness LA, Opitz JM, Gilbert-Barness E. Obesity: genetic, molecular, and environmental aspects. Am J Med Genet. 2007;143A(24): 30163034.

16. Calle EE, Thun MJ, Petrelli JM, Rodriguez C. Body-mass index and mortality in a prospective cohort of U.S. adults. N Engl J Med. 1999;341(15):1097-1105

17. Fried $\mathrm{M}$, Hainer $\mathrm{V}$, Basdevant $\mathrm{A}$, et al. Inter-disciplinary European guidelines on surgery of severe obesity. Int $J$ Obes (London). 2007;31(4):569-577.

18. Peeters A, Barendregt JJ, Willekens F, Mackenbach JP, et al. Obesity in adulthood and its consequences for life expectancy: A life-table analysis. Ann Intern Med. 2003;138(1):24-32.

19. Whitlock G, Lewington S, Sherliker P, et al. Body-mass index and causespecific mortality in adults: collaborative analyses of 57 prospective studies. Lancet. 2009;373(9669):1083-1096.

20. Finkelstein EA, Trogdon JG, Cohen JW, Dietz W. Annual medical spending attributable to obesity: payer-and service-specific estimates. Health Aff (Millwood). 2009; 28(5):822-831.

21. Hammond RA. The economic impact of obesity in the US. Brookings Institute. Sept 2010.

22. Heber D. An Integrative View of Obesity. Am $J$ Clin Nutr. 2010;9:280S-283S.

23. National Institutes of Health, The Practical Guide Identification, Evaluation and Treatment of Overweight and Obesity in Adults National Heart, Lung, and Blood Institute NIH Publication No. 00-4084 October U.S. Department of Health and Human Services, 2000

24. Haslam DW, James WP. Obesity. Lancet. 2005;366(9492):1197-1209.

25. Darvall KA, Sam RC, Silverman SH, Bradbury AW, Adam DJ. Obesity and thrombosis. Eur J Vasc Endovasc Surg. 2007;33(2):223-233.

26. Lee SD, Ju G, Choi JA, Kim JW, Yoon IY. The association of oxidative stress with central obesity in obstructive sleep apnea. Sleep Breath. 2011 May 26.

27. James WP. The fundamental drivers of the obesity epidemic. Obes Rev. 2008;S1:6-13.

28. Katsuki A, Sumida Y, Gabazza EC, et al. Plasma levels of agoutirelated protein are increased in obese men. J Clin Endocrinol Metab. 2001;86:1921.

29. Vassallo Josanne. Pathogenesis of obesity. Journal of the Malta College of Pharmacy Practice. 2007;12:19-22.

30. Farooqi IS, Jebb SA, Langmack G, et al. Effects of recombinant leptin therapy in a child with congenital leptin deficiency. N Engl J Med. 1999;341:879.

31. Bouchard C. Defining the genetic architecture of the predisposition to obesity: a challenging but not insurmountable task. Am J Clin Nutr. 2010;(91):5-6.

32. Heather A. Genetic Predisposition to Type 2 Diabetes Promotes Weight Gain. Garvan Institute of Medical Research http://www.eurekalert.org/ pub_releases/2010-05/ra-wgw051010.php.

33. Gardner DS, Hosking J, Metcalf BS, Jeffery AN, Voss LD, Wilkin T.J. Contribution of early weight gain to childhood overweight and metabolic health: a longitudinal study (Early Bird 36). Pediatrics, 2009;123(1):e6773.

34. Wang Gene-Jack, Nora D. Volkow, Joanna S. Fowler. The role of dopamine in motivation for food in humans: implications for obesity. Expert Opinion on Therapeutic Targets. 2002;6:601-609.

35. Romero-Corral A, Somers VK, Sierra-Johnson J, Korenfeld Y, Boarin S, Korinek J, et al. Normal weight obesity: a risk factor for cardiometabolic dysregulation and cardiovascular mortality. Eur Heart J. 2010;31:737746.

36. Kokkoris P, Pi-Sunyer FX. Obesity and endocrine disease. Endocrinol Metab Clin North Am. 2003;32:895-914.

37. Dietary Guidelines for Americans - U.S. Government Printing. Dietary Guidelines. gov/2010;

38. National Institute for Health and Clinical Excellence (NICE), (2006 and 2009) - Obesity: The prevention, identification, assessment and management of overweight and obesity in adults and children. London: NICE. www.nice.org.uk/guidance/CG43;

39. Wing Rena R, Phelan Suzanne. Science-Based Solutions to Obesity. Am J Clin Nutr. 2005;82(1 Suppl):207S-273S.

40. Tuomilehto J, Lindstrom J, Eriksson JG, et al. Prevention of Type 2 diabetes by changes in lifestyle among subjects with impaired glucose tolerance. N Engl J Med. 2001;344:1343-1350.

41. Wadden TA, Sternberg JA, Letizia KA, Stunkard AJ. Treatment of obesity by very low calorie diet, behaviour therapy and combination: a 5 year experience. Int J Obes. 1989;13S:39-46.

42. Dixon JB, et al. Adjustable gastric banding and conventional therapy for type 2 diabetes: a randomized controlled trial. JAMA. 2008;299:316323

43. Freitas A, Sweeney JF. Bariatric Surgery. In: B. Banerjee. Nutritiona Management of Digestive Disorders. Boca Raton, FL: CRC Press. 2010;327-342.

44. Shikora SA, Kim J, Tarnoff ME. Nutritional and gastrointestinal complications of bariatric surgery. Nutrition in Clinical Practice. 2007;22(1):29-40.

45. Sjostrom L, et al - Effects of bariatric surgery on mortality in Swedish obese subjects. N Engl J Med. 2007;357:741-752.

46. Thaler JP, Cummings DE - Minireview: Hormonal and metabolic mechanisms of diabetes remission after gastrointestinal surgery. Endocrinology. 2009;150:2518-2525.

47. Cummings DE. Endocrine mechanisms mediating remission of diabetes after gastric bypass surgery. Int J Obes (London). 2009;33(suppl 1):S33-S40.

48. Neff LM, Kushner RF. Emerging role of GLP-1 rec. agonists in the treatment of obesity. Diabetes Metab Syndr Obes. 2010;3:263-273. 